\title{
Identification of tapetum-specific genes by comparing global gene expression of four different male sterile lines in Brassica oleracea
}

\author{
Yuan Ma · Jungen Kang $\cdot$ Jian Wu $\cdot$ Yingguo Zhu • \\ Xiaowu Wang
}

Received: 24 April 2014 / Accepted: 19 January 2015 / Published online: 25 February 2015

(C) The Author(s) 2015. This article is published with open access at Springerlink.com

\begin{abstract}
The tapetum plays an important role in anther development by providing necessary enzymes and nutrients for pollen development. However, it is difficult to identify tapetum-specific genes on a large-scale because of the difficulty of separating tapetum cells from other anther tissues. Here, we reported the identification of tapetum-specific genes by comparing the gene expression patterns of four male sterile (MS) lines of Brassica oleracea. The abortive phenotypes of the four MS lines revealed different defects in tapetum and pollen development but normal anther wall development when observed by transmission electron microscopy. These tapetum displayed continuous defective characteristics throughout the anther developmental stages. The transcriptome from flower buds, covering all anther developmental stages, was analyzed and bioinformatics analyses exploring tapetum development-related genes were performed. We identified 1,005 genes differentially
\end{abstract}

Electronic supplementary material The online version of this article (doi:10.1007/s11103-015-0287-0) contains supplementary material, which is available to authorized users.

Y. Ma $\cdot$ Y. Zhu $(\bowtie)$

Key Laboratory of the Ministry of Education for Plant Developmental Biology, College of Life Sciences, Wuhan University, Wuhan 430072, China

e-mail: zhuyg@ public.wh.hb.cn

Y. Ma $\cdot$ J. Wu $\cdot$ X. Wang $(\bowtie)$

Institute of Vegetables and Flowers, Chinese Academy

of Agricultural Sciences, Zhongguancun South Street 12,

Beijing 100087, China

e-mail:wangxiaowu@caas.cn

J. Kang

Vegetable Research Center, Beijing Academy of Agriculture and Forestry Sciences, Landianchang South Street 5,

Beijing 100081, China expressed in at least one of the MS lines and 104 were non-pollen expressed genes (NPGs). Most of the identified NPGs were tapetum-specific genes considering that anther walls were normally developed in all four MS lines. Among the 104 NPGs, 22 genes were previously reported as being involved in tapetum development. We further separated the expressed NPGs into different developmental stages based on the MS defects. The data obtained in this study are not only informative for research on tapetum development in $B$. oleracea, but are also useful for genetic pathway research in other related species.

Keywords Brassica oleracea $\cdot$ Tapetum $\cdot$ Gene expression · Male sterility (MS) · Microarray

\section{Introduction}

Anther development comprises both gametophyte and anther wall development (Engelke et al. 2002; Ge et al. 2010; Ma and Sundaresan 2010). The connection between these two relatively independent processes occurs in the tapetum, a layer of the anther wall. As the innermost of four somatic layers, the tapetum surrounds developing reproductive cells and plays an important role in the male fertility of pollen grains. Its secretory tissue provides proteins, lipids, and other nutrients for pollen development and exine formation (Mariani et al. 1990; Piffanelli et al. 1998).

Anther development is divided into two main phases: microsporogenesis and microgametogenesis, and these are further subdivided into 14 anther stages (Chang et al. 2011; Ma 2005; Sanders et al. 1999; Smyth et al. 1990). In this research, to simplify these complex developmental processes, we divided these anther stages it into four major stages according to anther developmental events: 
Table 1 The description of four male sterile lines in this study

\begin{tabular}{lllll}
\hline MS materials & Types & Origins & Transfer methods & References \\
\hline NiCMS & Cytoplasmic male sterile & Brassica nigra & Protoplast fusion & Pearson 1972 \\
RGMS & Recessive male sterile & Brassica oleracea & Natural mutant & Fang et al. 1984 \\
OguCMS & Cytoplasmic male sterile & Raphanus sativus & Protoplast fusion & Kao et al. 1992 \\
DGMS & Dominant male sterile & Brassica oleracea & Natural mutant & Fang et al. 1995 \\
\hline
\end{tabular}

the sporogenesis cell stage, pollen mother cell stage, pretetrad stage, and post-tetrad stage. In the sporogenesis cell stage, the sporogenous cells, which give rise to pollen, are visible within locules of sectioned anthers (Goldberg et al. 1993; Scott et al. 1991, 2004), In the pollen mother cell stage, sporogenous cells develop into pollen mother cells (Owen and Makaroff 1995; Stevens and Murray 1981), In the pre-tetrad stage, microspore mother cells enter meiosis while the middle layer is crushed and degenerates. Tapetum becomes vacuolated and the anther undergoes a general increase in size. Tetrads of microspores are free within each locule when meiosis is completed in the tetrad stage. In the post-tetrad stage, the callose wall surrounding tetrads degenerates and individual microspores are released. Microspores generate an exine wall and become vacuolated (Sanders et al. 1999). After these four stages, tapetum degeneration is initiated. The tapetum undergoes generation, development, and apoptosis, providing enzymes for the release of microspores (Varnier et al. 2005). Eventually, all cell remnants are released into the locules, due to tapetal degeneration, and are integrated into the pollen wall as pollen coat material (Papini et al. 1999). This series of events is completed in a relatively short time, and the progression of stages involves changes in the expression levels of many genes. The identification of genes associated with tapetum-related processes helps build a solid foundation for studying the underlying molecular mechanisms of anther development.

Because of difficulties in separating the tapetum cell layer from other anther wall cell layers, the large-scale identification of tapetum cell-specific genes has not previously been achieved. Tapetum-specific genes have been identified by looking for male sterility (MS) mutants in Arabidopsis thaliana. Only a limited number of tapetumspecific genes were reported, these included ACOS5, A6, LTP12, LAP5, TSM1, TAP35, TAP44, and A9 (Ariizumi et al. 2002; de Azevedo et al. 2009; Fellenberg et al. 2008; Hird et al. 1993; Kim et al. 2010; Ma et al. 2012; Paul et al. 1992). Unfortunately, it is not possible to reveal the whole picture of tapetum gene expression by identifying specific tapetum gene mutants one by one. A large number of MS mutants have been identified from natural and artificial mutations in Brassica. Hybridization of $A$. thaliana cDNA arrays against close relatives that have bigger anthers, such as Brassica species, is a good approach for studying the genome-wide expression of anther-specific genes in Arabidopsis (Amagai et al. 2003).

Pollen grains can be easily isolated, which allows genes expressed in pollen grains to be easily profiled. A number of Arabidopsis pollen grain transcriptomes have been reported by Becker et al. (2003), Pina et al. (2005). Furthermore, a previous pollen transcriptome study by (Honys and Twell 2003) identified 992 pollen-expressed mRNAs, nearly $40 \%$ of which were detected specifically in pollen. They also (Honys and Twell 2004) developed specific spore isolation procedures for Arabidopsis at the pollen developmental stage, and used Affymetrix ATH1 genomic arrays to identify 13,977 male gametophyte-expressed mRNAs in all stages of microsporogenesis, $9.7 \%(1,355)$ of which were male gametophyte specific. However, comparative studies using the tapetum to identify anther wall-specific genes have not been reported in multiple MS lines in which MS mutants occur at different stages of tapetum development. Non-pollen expressed genes (NPGs), are the genes remaining after the exclusion of pollen-specific expressed genes from the genes expressed specifically in the anther. This provides a narrow range for the identification of potential tapetum-specific expressed genes.

This study employs four types of $B$. oleracea MS lines: Nigra cytoplasm male sterility (NiCMS), Ogura cytoplasm male sterility (OguCMS), recessive male sterility (RGMS) and dominant male sterility (DGMS) (Kang et al. 2008; Fang et al. 2001). Each MS line has a distinct tapetum abortion phenotype and their abnormal characteristics appear successively during anther development. For the large-scale identification of tapetum-specific genes and to gain further insight into downstream cellular reactions of tapetum development, we compared the anther transcriptomes of the four types of $B$. oleracea MS lines through the heterologous hybridization of $B$. oleracea mRNA onto an Arabidopsis whole genome oligonucleotide microarray.

\section{Materials and methods}

Plant materials

Four B. oleracea MS lines which are different from types and origins were used in this study (Table 1) (Kao et al. 1992; Pearson 1972; Fang et al. 1984, 1995): Nigra 
cytoplasmic MS line NiCMS-803B, recessive MS line RGMS-802B, Ogura cytoplasmic MS line OguCMSMsC-881, and dominant MS line DGMS-MsC-881, which were supplied by the Institute of Vegetables and Flowers, Chinese Academy of Agriculture Sciences. All four MS lines had been backcrossed to fertile parents for nine generations. All flower buds above the last opened flower of three flowering branches were collected from six MS plants and six corresponding control lines (MF; 803, 802, 881 , and $881 \mathrm{~K}$ ) during the full flowering stage for cytological observation and microarray experiments. All plants after vernalization were grown in a climate controlled greenhouse set at $70 \%$ relative humidity with a $20 / 15{ }^{\circ} \mathrm{C}$ (12 h/12 h) day/night temperature regime for 35-40 days.

\section{Cytological analysis using microscopes}

Light microscopy and transmission electron microscopy (TEM) were used to investigate the cytological differences between the mutants and wild-type. Different sized buds were fixed overnight in $4 \%$ glutaraldehyde with $200 \mathrm{mM}$ phosphate buffer $(\mathrm{pH} 7.0)$ and then rinsed overnight in $200 \mathrm{mM}$ phosphate buffer (pH 7.0). Next, buds were postfixed in a solution containing $1 \%$ osmium tetroxide for $2 \mathrm{~h}$ and washed in a dehydrated ethanol series for $30 \mathrm{~min}$ at each step $(2 \times 50,60,70,80,90$, and $2 \times 100 \%)$. Dehydrated tissues were embedded in Spurr's epoxy resin (Spurr 1969; Ted Pella, Redding, CA) for 3 days at $60^{\circ} \mathrm{C}$, and sectioned at $60-90 \mathrm{~nm}$ using a microtome (Leica Ultratome $\mathrm{V}$, LKB, Bromma, Sweden). Anther transverse sections were stained in $4 \%$ uranyl acetate for $20 \mathrm{~min}$ and in lead citrate for $3 \mathrm{~min}$. All specimens were analyzed using TEM (H-8100, Hitachi, Tokyo, Japan). For the light microscopy analysis, buds were fixed overnight in FAA (50\% ethanol, $5.0 \%$ glacial acetic acid, $3.7 \%$ formaldehyde), dehydrated in a graded ethanol series $(2 \times 50,60,70,85,95$, and $3 \times 100 \%$ ), embedded in Spurr's epoxy resin, and sectioned in $1 \mu \mathrm{m}$ thick slices using a microtome. Anther transverse sections were stained in $1 \%$ toluidine blue at $42{ }^{\circ} \mathrm{C}$ for $1-2 \mathrm{~h}$ and observed under a compound microscope (Olympus Model BH2, Tokyo, Japan).

RNA preparation, probe labeling, and microarray hybridization

For total RNA isolation, all flower buds above the last opened flowers of three flowering branches from three MS and three MF plants were collected in duplicate and combined to reduce plant-to-plant variation. Total RNA was isolated using TRIzol following the manufacturer's instructions (Invitrogen, Beijing, China). RNA was further purified using an RNeasy Mini kit (Qiagen China Co., Ltd., Shanghai, China) and the quality was checked using an
Agilent 2100 bioanalyzer (Agilent Technologies China Co., Ltd., Shanghai, China) and RNA 6000 Nano kit (Agilent Technologies China Co., Ltd., Shanghai, China) before labeled cRNA was synthesized. Cy3- and Cy5-labeled cRNA was synthesized from $400 \mathrm{ng}$ total RNA using a Low RNA Input Linear Amplification and Labeling kit Plus (Agilent Technologies China Co., Ltd., Shanghai, China) following manufacturer's protocol. Swap labeling of the other MS and MF (three plant pools) RNAs was conducted for the replications. Labeled cRNA was hybridized onto a $22 \mathrm{~K}$ Arabidopsis oligo microarray (Agilent Technologies China Co., Ltd., Shanghai, China) using the In situ Hybridization kit Plus (Agilent Technologies China Co., Ltd., Shanghai, China).

Data acquisition, normalization, and gene annotation analysis

Hybridized microarrays were scanned sequentially for Cy3and Cy5-labeled probes with a laser scanner (G2655AA, Agilent Technologies China Co., Ltd., Shanghai, China) at a resolution of $10 \mu \mathrm{m}$ and a PMT of 100 . The intensities were normalized by linear LOWESS (Yang et al. 2002). The signal was considered positive when the signal/noise value was $>5$. To determine pollen stage specificity and co-expression information, our data were compared with array data from two other studies. The pollen transcriptome refers to the dataset from (Honys and Twell 2004), and the stamen transcriptome refers to the dataset from (Wellmer et al. 2004). Microsoft Office Excel (Excel 2010, Microsoft China Co., Ltd., Beijing, China) was used to manage and filter the microarray data. Differently expressed genes (DEGs) were functionally categorized based on the ontology annotation of the Arabidopsis genome from the Arabidopsis Information Resource (http://www.arabidopsis. org). Pollen expression type was determined based on the maximum expression value (MaxP) from the four pollen stages (uninucleate microspore, bicellular pollen, tricellular pollen, and mature pollen), the maximum expression value (MaxS) from seven sporophytic tissues (cotyledon, leaves, petiole, stems, roots, root hair zone, and suspension cell cultures), or the value of MaxP/MaxS according to the pollen transcriptome dataset (Honys and Twell 2004). Late pollen genes were defined as those expressed after microspore mitosis during male gametophyte development, which had continued transcript accumulation during pollen maturation (McCormick 1993).

Reverse transcription-polymerase chain reaction (RT-PCR)

Total RNA was treated with RNase-free DNase (Promega China Co., Ltd., Beijing, China) to remove genomic DNA. RT-PCR reactions were conducted using first-strand 
cDNA synthesized from $2 \mu \mathrm{g}$ total RNA with Superscript II Transcriptase (Invitrogen, Beijing, China) and a poly$\mathrm{dT}_{18}$ primer (Takara, Tokyo, Japan). The cDNAs were then used as templates for RT-PCR with gene-specific primers designed based on reference sequences of B. oleracea ssp. capitata line 02-12 retrieved from BRAD (http://brassicadb.org/brad; Table 2). The Translation Elongation Factor gene $E F-1 \alpha$ was used as a positive control togage the quantity of input cDNA among the different samples. The primers used are listed in Supplementary Table S5.

In situ hybridization

Arabidopsis Col-0 inflorescences were embedded in Paraplast (Sigma-Aldrich, Shanghai, China), sectioned at $8-\mu \mathrm{m}$ thickness and mounted onto precharged slides. For sense and antisense probe synthesis, five coding regions of the NPGs, MEE48, A9, CYP98A8, EXL6, and GGPS5, resulting in 990-, 895-, 749-, 552-, and 656-bp DNA templates, were PCR amplified from flower cDNA using gene-specific forward and reverse primers. A T7 polymerase binding site was incorporated into the forward primer for sense probe amplification and in the reverse primer for antisense probe amplification. Digoxigenin-labeled probes were transcribed off the template using T7 polymerase (Roche, Shanghai, China). Probes were shortened to 200-bp fragments by limited carbonate hydrolysis, and then quantified and hybridized to slides. Tissue fixation, embedding, hybridization, and signal detection were performed as described by (Hooker et al. 2002).

\section{Results and discussion}

Cytological defects in the four $B$. oleracea MS lines

The correct spatiotemporal expression of genes in the anther is required for normal tapetum development. We clarified the sequential appearance and characteristics of the cytological defects of the four B. oleracea MS lines by comparing them with the wild-type (Fig. 1I). Light microscopy of the main anther developmental stages revealed that the abortive phenotypes appeared successively in the NiCMS line (Fig. 1I-7), the RGMS line (Fig. 1I-14), the OguCMS line (Fig. 1I-21), and finally in the DGMS line (Fig. 1I-28). We performed a TEM analysis to characterize the defective tapetum development in the four MS mutant lines (Fig. 1II). In the wild-type line, the sporogenous cells, which give rise to pollen, are visible within locules of sectioned anthers. Concentric rings of other cell types associated with pollen development and release are differentiated around the sporogenous cells during the sporogenesis cell stage (Fig. 1II-1). Sporogenous cells develop into microspore mother cells and four single distinguishable layers of anther wall and microsporangium could be observed during the microspore mother cell stage (Fig. 1II2). Tetrads and tapetum with normal structures, as well as a single microspore tetrad with a central large nucleus, thick cytoplasm and abundant mitochondria develop during the tetrad stage (Fig. 1II-3).Vacuolated epidermal and endothelial cells, degenerating tapetum, and a free uninucleated microspore, containing a central nucleus, clear nuclear membrane, thick cytoplasm, and abundant plastids, appear in the post-tetrad stage (Fig. 1II-4). We compared the cytological features of the four male sterility types with those of wild-type. For each, we observed unique defective features. In the NiCMS line, the tapetal cells differentiated inconspicuously, with an indistinguishable middle layer at the sporogenesis cell stage (Fig. 1II-5). In the RGMS line, the tetrad aborted once it was formatted and the tapetal separated from anther wall at the microspore mother stage (Fig. 1II-6). In the OguCMS line, the tapetums were abnormally activated and thickened continuously when meiosis finished during the early tetrad stage (Fig. 1II-7). In the DGMS line, the morphology of the tapetum was not affected (Fig. 1II-8), as reported by (Lou et al. 2007). The development of microspores in the four MS lines was affected at different stages because of the abnormal tapetum development.

Genes with depressed expression levels became the focus of the research because the cytological observations indicated that MS lines were blocked by separate MS proteins. We hypothesized that a sequential developmental interruption model would clarify the gene expression sequence and be in accordance with the cytological results (Fig. 2). Based on the appearance point of the four MS phenotypes (NiCMS earlier than RGMS, RGMS earlier than OguCMS, OguCMS earlier than DGMS), the genes down-regulated only in the NiCMS lines were considered to express earlier than the genes down-regulated in both NiCMS and RGMS lines, and the genes down-regulated in both NiCMS and RGMS lines were considered to express earlier than the genes down-regulated in NiCMS, RGMS, and OguCMS lines. The latest expressing genes would be those that were down-regulated in all four MS lines. Genes involving in anther development mainly express in time series. The accumulation of products produced by early-expressing genes, such as transcription factors and secreted proteins., play important roles in expression of late-expressing genes (Wilson and Zhang 2009).

\section{Signal extraction of the microarrays}

To reduce plant to plant and inflorescence branch-to-branch variations, we pooled the RNA obtained from three different plants. Pooling RNA before labeling has the advantage 
Table 2 The 104 non-pollen expressed genes (NPGs) from Brassica oleracea detected in this study

\begin{tabular}{|c|c|c|c|c|c|c|c|}
\hline \multirow[t]{2}{*}{ Gene ID } & \multirow[t]{2}{*}{ Group name } & \multirow[t]{2}{*}{ Gene description } & \multicolumn{4}{|c|}{$\begin{array}{l}\text { Down-regulated ratio of fertility to } \\
\text { sterility F/S }\end{array}$} & \multirow[t]{2}{*}{ Expression pattern groups } \\
\hline & & & NiCMS & RGMS & OguCMS & DGMS & \\
\hline AT1G01280 & CYP703A2 & $\begin{array}{l}\text { Cytochrome } \mathrm{P} 450 \text {, family } 703 \text {, subfamily A, } \\
\text { polypeptide } 2\end{array}$ & 59.137 & 0.499 & 0.687 & 1.923 & A \\
\hline AT1G03390 & & HXXXD-type acyl-transferase family protein & 3.376 & 0.819 & 0.309 & 0.931 & A \\
\hline AT1G27040 & & Major facilitator superfamily protein & 3.664 & 2.117 & 2.985 & 1.008 & A \\
\hline AT1G36340 & $U B C 31$ & Ubiquitin-conjugating enzyme 31 & 3.503 & 1.161 & 1.566 & 0.906 & A \\
\hline AT1G52560 & & HSP20-like chaperones superfamily protein & 49.751 & 1.362 & 1.769 & 0.772 & A \\
\hline AT1G62940 & ACOS5 & Acyl-CoA synthetase 5 & 21.156 & 0.364 & 0.403 & 1.246 & A \\
\hline AT1G74310 & HSP101 & Heat shock protein 101 & 9.024 & 0.971 & 0.957 & 2.327 & A \\
\hline AT2G14540 & $S R P 2$ & Serpin 2 & 8.913 & 0.378 & 0.857 & 2.331 & A \\
\hline AT2G26150 & HSFA2 & Heat shock transcription factor A2 & 4.045 & 0.955 & 1.087 & 2.105 & A \\
\hline AT2G31210 & & $\begin{array}{l}\text { Basic helix-loop-helix (bHLH) DNA-binding } \\
\text { superfamily protein }\end{array}$ & 3.998 & 2.032 & 0.512 & 0.969 & A \\
\hline AT2G38240 & & $\begin{array}{l}\text { 2-oxoglutarate (2OG) and } \mathrm{Fe}(\mathrm{II}) \text {-dependent } \\
\text { oxygenase superfamily protein }\end{array}$ & 3.035 & 1.621 & 1.630 & 0.377 & $\mathrm{~A}$ \\
\hline AT2G42940 & & Predicted AT-hook DNA-binding family protein & 36.341 & 0.336 & 0.086 & 2.476 & A \\
\hline AT2G45630 & & $\begin{array}{l}\text { D-isomer specific 2-hydroxyacid dehydrogenase } \\
\text { family protein }\end{array}$ & 3.502 & 1.118 & 1.133 & 1.450 & A \\
\hline AT3G05780 & LON3 & lon protease 3 & 3.075 & 0.311 & 0.330 & 0.898 & A \\
\hline AT3G09640 & $A P X 2$ & Ascorbate peroxidase 2 & 7.165 & 1.048 & 2.410 & 0.905 & A \\
\hline AT3G13220 & $W B C 27$ & ABC-2 type transporter family protein & 15.681 & 0.560 & 0.704 & 1.188 & $\mathrm{~A}$ \\
\hline AT3G48540 & & $\begin{array}{l}\text { Cytidine/deoxycytidylate deaminase family } \\
\text { protein }\end{array}$ & 3.199 & 1.013 & 0.845 & 0.817 & A \\
\hline AT3G52130 & & $\begin{array}{l}\text { Bifunctional inhibitor/lipid-transfer protein/seed } \\
\text { storage } 2 \mathrm{~S} \text { albumin superfamily protein }\end{array}$ & 9.011 & 0.495 & 0.245 & 0.654 & $\mathrm{~A}$ \\
\hline AT4G14080 & MEE48 & O-Glycosyl hydrolases family 17 protein & 85.174 & 0.322 & 0.406 & 1.871 & A \\
\hline AT4G20800 & & FAD-binding Berberine family protein & 3.556 & 0.216 & 0.478 & 0.496 & A \\
\hline AT4G34850 & LAP5 & Chalcone and stilbene synthase family protein & 33.679 & 0.347 & 0.524 & 2.273 & A \\
\hline AT5G02490 & Hsp70-2 & Heat shock protein 70 (Hsp 70) family protein & 3.638 & 0.991 & 0.994 & 1.583 & A \\
\hline AT5G03800 & EMB1899 & $\begin{array}{l}\text { Pentatricopeptide repeat (PPR) superfamily } \\
\text { protein }\end{array}$ & 3.957 & 0.603 & 0.398 & 1.511 & $\mathrm{~A}$ \\
\hline AT5G07230 & & $\begin{array}{l}\text { Bifunctional inhibitor/lipid-transfer protein/seed } \\
\text { storage } 2 \mathrm{~S} \text { albumin superfamily protein }\end{array}$ & 38.418 & 1.387 & 1.473 & 1.206 & A \\
\hline AT5G15250 & FTSH6 & FTSH protease 6 & 6.159 & 0.940 & 1.604 & 0.937 & A \\
\hline AT5G56110 & MYB80 & myb domain protein 103 & 11.942 & 0.297 & 0.310 & 1.641 & $\mathrm{~A}$ \\
\hline AT5G59330 & & $\begin{array}{l}\text { Bifunctional inhibitor/lipid-transfer protein/seed } \\
\text { storage } 2 \mathrm{~S} \text { albumin superfamily protein }\end{array}$ & 3.228 & 0.863 & 1.869 & 0.416 & A \\
\hline AT5G66110 & HIPP27 & $\begin{array}{l}\text { Heavy metal transport/detoxification superfamily } \\
\text { protein }\end{array}$ & 4.063 & 0.950 & 1.877 & 1.133 & A \\
\hline AT1G06170 & & $\begin{array}{l}\text { Basic helix-loop-helix (bHLH) DNA-binding } \\
\text { superfamily protein }\end{array}$ & 21.653 & 3.183 & 0.946 & 1.042 & $\mathrm{~B}$ \\
\hline AT1G26780 & MYB117 & myb domain protein 117 & 5.846 & 3.004 & 2.601 & 1.306 & $\mathrm{~B}$ \\
\hline AT1G61070 & $P D F 2.4$ & low-molecular-weight cysteine-rich 66 & 19.633 & 6.853 & 1.030 & 0.804 & $\mathrm{~B}$ \\
\hline AT2G16910 & $A M S$ & $\begin{array}{l}\text { Basic helix-loop-helix (bHLH) DNA-binding } \\
\text { superfamily protein }\end{array}$ & 66.945 & 4.721 & 0.651 & 1.476 & $\mathrm{~B}$ \\
\hline AT3G13890 & MYB26 & myb domain protein 26 & 4.193 & 5.225 & 2.197 & 0.996 & $\mathrm{~B}$ \\
\hline AT5G09970 & CYP78A7 & $\begin{array}{l}\text { Cytochrome P450, family } 78 \text {, subfamily A, } \\
\text { polypeptide } 7\end{array}$ & 27.337 & 10.050 & 0.731 & 0.837 & $\mathrm{~B}$ \\
\hline AT5G59720 & HSP18.2 & Heat shock protein 18 & 61.107 & 3.567 & 2.700 & 1.710 & $\mathrm{~B}$ \\
\hline AT1G06260 & & Cysteine proteinases superfamily protein & 73.654 & 73.422 & 81.181 & 1.410 & $\mathrm{C}$ \\
\hline
\end{tabular}


Table 2 continued

\begin{tabular}{|c|c|c|c|c|c|c|c|}
\hline \multirow[t]{2}{*}{ Gene ID } & \multirow[t]{2}{*}{ Group name } & \multirow[t]{2}{*}{ Gene description } & \multicolumn{4}{|c|}{$\begin{array}{l}\text { Down-regulated ratio of fertility to } \\
\text { sterility F/S }\end{array}$} & \multirow[t]{2}{*}{ Expression pattern groups } \\
\hline & & & NiCMS & RGMS & OguCMS & DGMS & \\
\hline AT1G06990 & & $\begin{array}{l}\text { GDSL-like Lipase/Acylhydrolase superfamily } \\
\text { protein }\end{array}$ & 35.896 & 27.959 & 28.634 & 1.008 & $\bar{C}$ \\
\hline AT1G09550 & & Pectinacetylesterase family protein & 10.316 & 7.484 & 7.553 & 2.254 & $\mathrm{C}$ \\
\hline AT1G61110 & NAC025 & NAC domain containing protein 25 & 100.000 & 42.366 & 100.000 & 1.177 & $\mathrm{C}$ \\
\hline AT1G66570 & SUC7 & Sucrose-proton symporter 7 & 12.623 & 5.220 & 8.168 & 2.813 & $\mathrm{C}$ \\
\hline AT1G68190 & & B-box zinc finger family protein & 9.385 & 3.859 & 4.895 & 1.220 & $\mathrm{C}$ \\
\hline AT1G71160 & KCS7 & 3-ketoacyl-CoA synthase 7 & 40.698 & 7.545 & 4.751 & 1.043 & $\mathrm{C}$ \\
\hline AT1G74540 & СУР98А & $\begin{array}{l}\text { Cytochrome P450, family } 98 \text {, subfamily A, } \\
\text { polypeptide } 8\end{array}$ & 66.968 & 10.829 & 45.078 & 1.006 & $\mathrm{C}$ \\
\hline AT1G75930 & EXL6 & Extracellular lipase 6 & 41.703 & 29.272 & 31.621 & 1.245 & $\mathrm{C}$ \\
\hline AT2G03850 & & $\begin{array}{l}\text { Late embryogenesis abundant protein (LEA) } \\
\text { family protein }\end{array}$ & 95.261 & 66.233 & 85.170 & 1.376 & $\mathrm{C}$ \\
\hline AT2G23800 & GGPS5 & Geranylgeranyl pyrophosphate synthase 2 & 6.929 & 5.344 & 4.895 & 1.002 & $\mathrm{C}$ \\
\hline AT3G51590 & LTP12 & Lipid transfer protein 12 & 73.651 & 29.780 & 100.000 & 1.015 & $\mathrm{C}$ \\
\hline AT3G56380 & $R R 17$ & Response regulator 17 & 3.141 & 3.041 & 3.287 & 0.988 & $\mathrm{C}$ \\
\hline AT5G14980 & & Alpha/beta-Hydrolases superfamily protein & 11.521 & 5.466 & 5.219 & 1.233 & $\mathrm{C}$ \\
\hline AT5G38160 & & $\begin{array}{l}\text { Bifunctional inhibitor/lipid-transfer protein/seed } \\
\text { storage } 2 \mathrm{~S} \text { albumin superfamily protein }\end{array}$ & 85.213 & 3.937 & 4.407 & 0.819 & $\mathrm{C}$ \\
\hline AT5G57670 & & Protein kinase superfamily protein & 5.306 & 7.763 & 6.793 & 2.440 & $\mathrm{C}$ \\
\hline AT1G30860 & & RING/U-box superfamily protein & 11.670 & 7.714 & 15.767 & 12.143 & $\mathrm{D}$ \\
\hline AT1G60210 & & Unknown & 10.368 & 4.913 & 10.225 & 5.278 & $\mathrm{D}$ \\
\hline AT2G47040 & $V G D 1$ & $\begin{array}{l}\text { Plant invertase/pectin methylesterase inhibitor } \\
\text { superfamily }\end{array}$ & 85.995 & 94.127 & 100.000 & 13.393 & $\mathrm{D}$ \\
\hline AT4G37960 & & Unknown & 91.658 & 100.000 & 100.000 & 8.117 & $\mathrm{D}$ \\
\hline AT1G27720 & $T A F 4 B$ & TBP-associated factor $4 \mathrm{~B}$ & 0.600 & 1.203 & 0.317 & 1.100 & OguCMS_UP \\
\hline AT1G60500 & $D R P 4 C$ & Dynamin related protein $4 \mathrm{C}$ & 0.460 & 0.735 & 0.236 & 0.942 & OguCMS_UP \\
\hline AT1G68640 & $P A N$ & bZIP transcription factor family protein & 0.961 & 0.742 & 0.258 & 0.738 & OguCMS_UP \\
\hline AT2G23050 & NPY4 & Phototropic-responsive NPH3 family protein & 0.760 & 0.777 & 0.216 & 0.888 & OguCMS_UP \\
\hline AT3G13960 & GRF5 & Growth-regulating factor 5 & 0.714 & 1.087 & 0.327 & 0.957 & OguCMS_UP \\
\hline AT3G19300 & & Protein kinase superfamily protein & 0.692 & 0.820 & 0.252 & 0.949 & OguCMS_UP \\
\hline AT4G10640 & $I Q D 16$ & IQ-domain 16 & 0.411 & 0.736 & 0.280 & 0.835 & OguCMS_UP \\
\hline AT4G29980 & & & 2.059 & 0.561 & 0.221 & 0.826 & OguCMS_UP \\
\hline AT5G13170 & SWEET15 & Senescence-associated gene 29 & 1.399 & 0.943 & 0.297 & 0.678 & OguCMS_UP \\
\hline AT5G26140 & $L O G 9$ & Putative lysine decarboxylase family protein & 1.131 & 1.406 & 0.333 & 0.743 & OguCMS_UP \\
\hline AT5G41890 & & $\begin{array}{l}\text { GDSL-like Lipase/Acylhydrolase superfamily } \\
\text { protein }\end{array}$ & 1.215 & 1.296 & 0.303 & 0.813 & OguCMS_UP \\
\hline AT5G42120 & & $\begin{array}{l}\text { Concanavalin A-like lectin protein kinase family } \\
\text { protein }\end{array}$ & 0.763 & 0.724 & 0.168 & 0.837 & OguCMS_UP \\
\hline AT5G63390 & & O-fucosyltransferase family protein & 0.548 & 0.840 & 0.334 & 1.347 & OguCMS_UP \\
\hline AT1G26400 & & FAD-binding Berberine family protein & 0.977 & 0.093 & 0.206 & 0.381 & RGMS \& OguCMS_UP \\
\hline AT1G53990 & GLIP3 & GDSL-motif lipase 3 & 0.849 & 0.166 & 0.217 & 0.612 & RGMS \& OguCMS_UP \\
\hline AT1G73050 & & $\begin{array}{l}\text { Glucose-methanol-choline (GMC) oxidoreduc- } \\
\text { tase family protein }\end{array}$ & 0.807 & 0.264 & 0.075 & 0.482 & RGMS \& OguCMS_UP \\
\hline AT3G21660 & & UBX domain-containing protein & 1.380 & 0.249 & 0.100 & 0.865 & RGMS \& OguCMS_UP \\
\hline AT5G54060 & $U F 3 G T$ & UDP-glucose:flavonoid 3-o-glucosyltransferase & 1.248 & 0.331 & 0.324 & 1.486 & RGMS \& OguCMS_UP \\
\hline AT5G10880 & & tRNA synthetase-related/tRNA ligase-related & 1.794 & 0.517 & 0.190 & 0.287 & OguCMS \& DGMS_UP \\
\hline AT1G69500 & CYP704B1 & $\begin{array}{l}\text { Cytochrome P450, family 704, subfamily B, } \\
\text { polypeptide } 1\end{array}$ & 80.639 & 5.991 & 0.789 & 1.331 & \\
\hline
\end{tabular}


Table 2 continued

\begin{tabular}{|c|c|c|c|c|c|c|c|}
\hline \multirow[t]{2}{*}{ Gene ID } & \multirow[t]{2}{*}{ Group name } & \multirow[t]{2}{*}{ Gene description } & \multicolumn{4}{|c|}{$\begin{array}{l}\text { Down-regulated ratio of fertility to } \\
\text { sterility F/S }\end{array}$} & \multirow[t]{2}{*}{ Expression pattern groups } \\
\hline & & & NiCMS & RGMS & OguCMS & DGMS & \\
\hline AT1G75890 & & $\begin{array}{l}\text { GDSL-like Lipase/Acylhydrolase superfamily } \\
\text { protein }\end{array}$ & 11.565 & 3.048 & 8.453 & 1.224 & \\
\hline AT3G10600 & $C A T 7$ & Cationic amino acid transporter 7 & 2.700 & 4.204 & 1.349 & 1.514 & \\
\hline AT3G15870 & & Fatty acid desaturase family protein & 0.347 & 3.419 & 0.741 & 1.786 & \\
\hline AT1G64010 & & $\begin{array}{l}\text { Serine protease inhibitor (SERPIN) family } \\
\text { protein }\end{array}$ & 20.572 & 0.279 & 1.114 & 3.002 & \\
\hline AT3G11980 & MS2 & $\begin{array}{l}\text { Jojoba acyl CoA reductase-related male sterility } \\
\text { protein }\end{array}$ & 88.115 & 0.664 & 0.728 & 5.882 & \\
\hline AT2G13900 & & $\begin{array}{l}\text { Cysteine/Histidine-rich } \mathrm{C} 1 \text { domain family } \\
\text { protein }\end{array}$ & 10.295 & 14.914 & 16.371 & 6.944 & \\
\hline AT1G28430 & CYP705A24 & $\begin{array}{l}\text { Cytochrome } \mathrm{P} 450 \text {, family } 705 \text {, subfamily A, } \\
\text { polypeptide } 24\end{array}$ & 5.695 & 2.973 & 5.814 & 1.383 & \\
\hline AT2G14960 & GH3.1 & Auxin-responsive GH3 family protein & 3.708 & 0.732 & 3.282 & 1.158 & \\
\hline AT3G27812 & & Unknown & 18.284 & 0.542 & 43.198 & 1.023 & \\
\hline AT3G53290 & $C Y P 71 B 30 P$ & $\begin{array}{l}\text { Cytochrome } \mathrm{P} 450 \text {, family } 71 \text {, subfamily } \mathrm{B} \text {, poly- } \\
\text { peptide } 30 \text { pseudogene }\end{array}$ & 9.250 & 0.375 & 16.667 & 1.371 & \\
\hline AT3G55970 & $J R G 21$ & Jasmonate-regulated gene 21 & 5.141 & 0.497 & 4.167 & 0.781 & \\
\hline AT3G56700 & FAR6 & Fatty acid reductase 6 & 16.177 & 0.353 & 100.000 & 1.551 & \\
\hline AT1G03170 & $F A F 2$ & Protein of unknown function (DUF3049) & 0.681 & 0.673 & 3.176 & 1.515 & \\
\hline AT1G15360 & WIN1 & Integrase-type DNA-binding superfamily protein & 1.929 & 1.215 & 4.281 & 1.031 & \\
\hline AT1G19640 & $J M T$ & Jasmonic acid carboxyl methyltransferase & 1.141 & 0.772 & 5.879 & 1.379 & \\
\hline AT1G30740 & & FAD-binding Berberine family protein & 2.387 & 2.498 & 4.238 & 2.632 & \\
\hline AT2G19990 & $P R-1-L I K E$ & Pathogenesis-related protein-1-like & 1.504 & 2.561 & 6.212 & 5.556 & \\
\hline AT2G21220 & & SAUR-like auxin-responsive protein family & 1.133 & 1.327 & 4.282 & 1.002 & \\
\hline AT2G23570 & MES19 & Methyl esterase 19 & 1.984 & 0.226 & 4.238 & 0.509 & \\
\hline AT2G30310 & & GDSL-like Lipase/Acylhydrolase family protein & 2.397 & 1.417 & 3.256 & 1.043 & \\
\hline AT3G10570 & CYP77A6 & $\begin{array}{l}\text { Cytochrome P450, family 77, subfamily A, } \\
\text { polypeptide } 6\end{array}$ & 1.852 & 1.168 & 3.098 & 0.842 & \\
\hline AT3G57510 & $A D P G 1$ & Pectin lyase-like superfamily protein & 1.774 & 1.043 & 5.391 & 1.049 & \\
\hline AT4G16000 & & & 0.601 & 0.850 & 4.465 & 0.886 & \\
\hline AT4G37950 & & Rhamnogalacturonate lyase family protein & 2.729 & 1.904 & 3.469 & 2.782 & \\
\hline AT5G62320 & MYB99 & myb domain protein 99 & 30.564 & 0.958 & 4.055 & 1.460 & \\
\hline AT1G13150 & CYP86C4 & $\begin{array}{l}\text { Cytochrome } \mathrm{P} 450 \text {, family } 86 \text {, subfamily } \mathrm{C} \text {, } \\
\text { polypeptide } 4\end{array}$ & 77.360 & 21.613 & 43.020 & 1.065 & \\
\hline AT3G59440 & & Calcium-binding EF-hand family protein & 1.879 & 4.605 & 3.068 & 1.951 & \\
\hline AT4G12410 & & SAUR-like auxin-responsive protein family & 1.413 & 3.016 & 8.257 & 0.898 & \\
\hline AT4G23230 & CRK15 & $\begin{array}{l}\text { Cysteine-rich RLK (RECEPTOR-like protein } \\
\text { kinase) } 15\end{array}$ & 13.486 & 7.928 & 8.071 & 1.337 & \\
\hline
\end{tabular}

OguCMS_UP represents NPGs only up-regulated in the OguCMS line; RGMS \& OguCMS_UP represents NPGs up-regulated in both the RGMS and OguCMS lines; OguCMS \& DGMS_UP represents NPGs up-regulated in both the OguCMS and DGMS lines

A, B, C, and D present the expression order of down-regulated NPGs following the sequence of the abortive phenotypes appearance in the four male sterile (MS) lines of Brassica oleracea observed by light microscopy

of reducing the variation due to biological replication and sample handling. Two replicate hybridizations were performed using pooled RNA from three different sterile or fertile plants and the labels were swapped for the second slide, with biological replicates. After the quantification of the signal intensities, the data were normalized to compensate for the nonlinearity of intensity distributions and differences in probe labeling (Fig. 3). Using a signal/noise value $>5$ to select for positive signals, we detected 12,838 positive signals both in NiCMS control samples and NiCMS 
samples; 13,037 positive signals both in RGMS control samples and RGMS samples; 13,083 positive signals both in OguCMS control samples and OguCMS samples; and 11,581 positive signals both in DGMS control samples and DGMS samples. The reproducibility was determined by calculating the coefficient $\left(R^{2}\right)$ of the $\log _{2}$ normalized signal values of all detected signals. The $\mathrm{R}^{2}$-value between replicas were as follows: 0.9847 for the NiCMS control (Fig. 3a) and 0.9808 for the NiCMS samples (Fig. 3b);

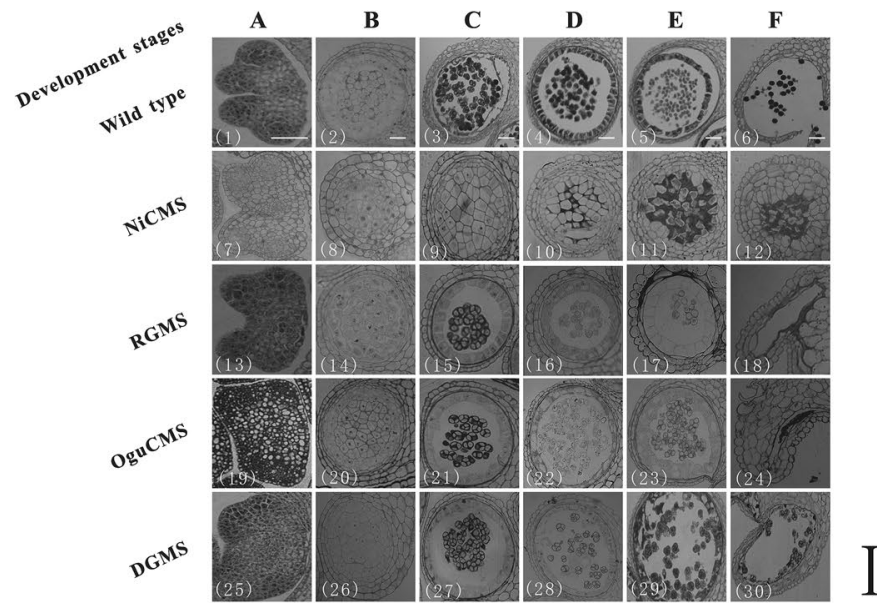

Fig. 1 Light and transmission electron microscopy (TEM) micrographs of tapetums in wild-type and the four male sterile (MS) lines of Brassica oleracea at different developmental stages. I Comparisons of anther development between the wild-type (1-6) and four MS lines, NiCMS (7-12), RGMS (13-18), OguCMS (19-24), and DGMS (25-30), at different developmental stages, revealing that the principal cause of abnormal anther development in the four MS lines are defects in tapetum development, followed by abnormalities in microspore development. Bar $=20 \mu \mathrm{m}$. II Comparisons of tapetum development between the wild-type (1-4) and the four MS lines
Fig. 3 The correlation analysis between two swap replicates of the four male sterile (MS) lines of Brassica oleracea and corresponding control line (MF) buds. a NiCMS control; b NiCMS; c RGMS control; d RGMS; e OguCMS control; f OguCMS; g DGMS control; and h DGMS

0.9754 for the RGMS control samples (Fig. 3c) and 0.9663 for the RGMS samples (Fig. 3d); 0.9708 for the OguCMS control samples (Fig. 3e) and 0.9834 for the OguCMS
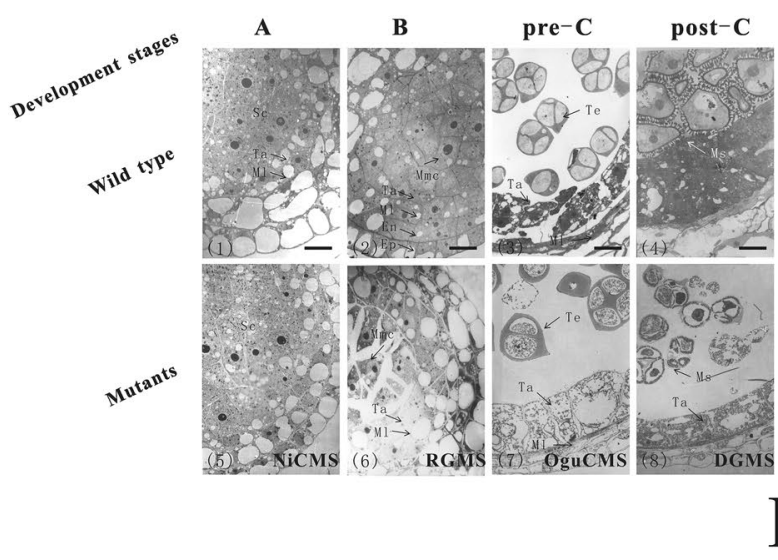

at different developmental stages (5-8), revealing that the sequence appearance and characteristics of tapetum cytological defects at the sporogenesis cell stage, microspore mother cell stage, pre-tetrad stage and post-tetrad stage. $B a r=2 \mu \mathrm{m}$. A the sporogenesis cell stage; $B$ the microspore mother cell stage; $C$ the early tetrad stage; $D$ the uninucleate microspore stage; $E$ the mature pollen stage; and $F$ the dehiscence stage. $S c$ sporogenesis cell, $T a$ tapetum, $M l$ middle layer, $M m c$ microspore mother cell, En endothecium cell, Ep epidermis cell, $T e$ tetrad, $M s$ microspore

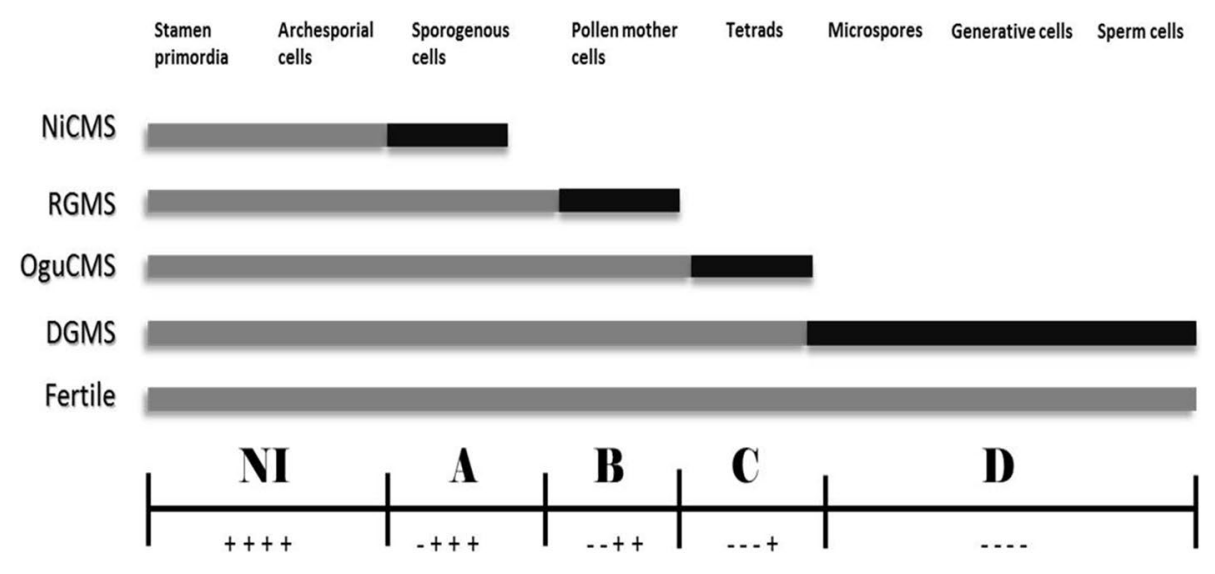

Fig. 2 Sequential developmental interruption model for the four types of male sterile (MS) lines of B. oleracea. Gray bar represents the normal developmental stage. Black bar represents the male sterility stage. NI represents the stage in which the genes were not interrupted in all four MS lines. $A, B, C$, and $D$ represent the expressed genes in different anther developmental stages, which were classified by the developmental interruptions of NiCMS, RGMS, OguCMS and DGMS, respectively. Plus represent up-regulated and minus represent down-regulated 

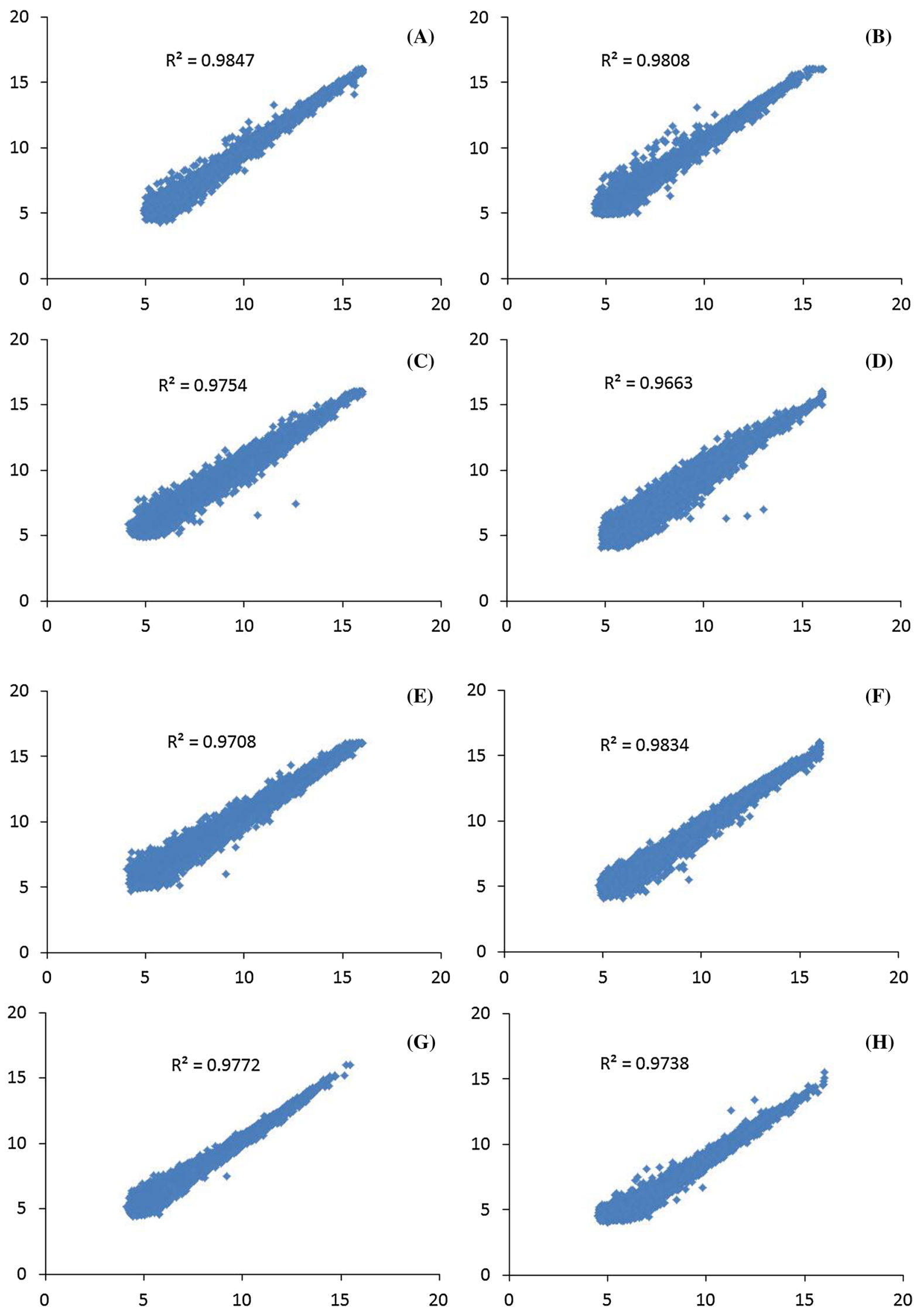
Fig. 4 RT-PCR expression patterns of nine randomly selected genes. $N, R, O, D$ represents the four male sterile (MS) lines of Brassica oleracea, NiCMS, RGMS, OguCMS, and DGMS. $F-N, F-R, F-O, F-D$ represents the four MS lines' corresponding control lines (MFs)

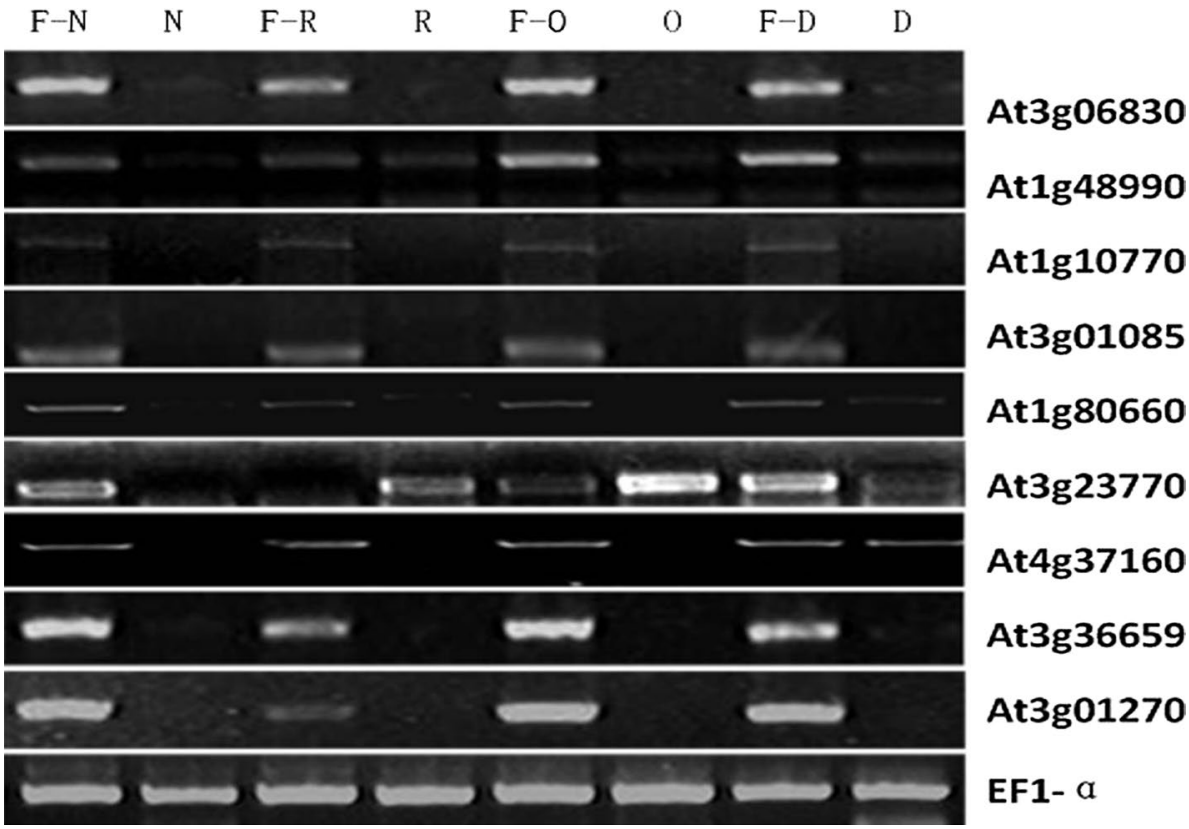

There were 544, 338, 526, and 209 down-regulated genes, and 5, 45, 151, and 15 up-regulated genes detected in the NiCMS, RGMS, OguCMS, and DGMS lines, respectively (Supplementary Table S2 and S3). After redundant genes were merged, 838 DEGs were down-regulated (group 1) and 188 up-regulated (group 2) in at least one of the four MS lines. The overlap of group 1 and group 2 contained 21 DEGs, including the two tapetum-related genes TDF1 and MYB 103. These genes play vital roles in tapetum synthesis and degeneration, and the sporopollenin monomer biosynthesis process (Higginson et al. 2003). These genes were down-regulated in the NiCMS line but up-regulated in RGMS and OguCMS lines. Following the removal of these 21 DEGs, 1,005 non-redundant DEGs were identified in this research.

\section{Identification of tapetum-specific genes}

The tapetum has been studied in many kinds of plants using MS defects, and, due to the difficulty of tapetum isolation, only four genes have been reported to be tapetum specific by MS mutant gene cloning (Suwabe et al. 2008). Therefore, we developed an approach to identify tapetumspecific genes on a large-scale, and at the developmental stages in which they are expressed. Fortunately, the separation of male gametophytes is easy, and numerous male gametophyte-specific genes have been identified from multiple MS mutants and global transcriptome analyses.

To identify genes specifically involved in tapetum development, we removed genes known to be expressed in sporophytic tissues based on the findings of Honys and Twell 2004. Their research identified 17,677 sporophytic genes, 


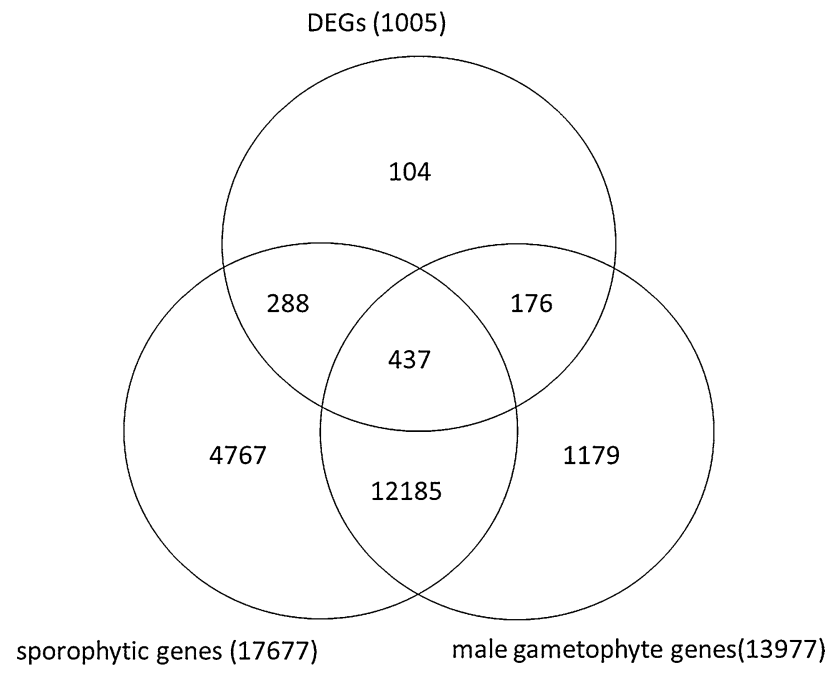

Fig. 5 Comparison between differentially expressed genes (DEGs) and genes expressed in sporophytic and gametophytic tissues to identify non-pollen expressed genes (NPGs) of B. oleracea. A total of 17,677 sporophytic-expressed genes and 13,977 male gametophyteexpressed genes were detected in Honys' research (Honys and Twell 2004). Of the DEGs, 725 genes were also sporophytic-expressed genes and 613 were also male gametophyte-expressed genes

of which 725 genes overlapped with the 1,005 DEGs identified in our research (Supplementary Table S4). This left 280 DEGs thought to be expressed specifically in the anthers. Furthermore, 176 male-gametophyte expressed DEGs identified by (Honys and Twell 2004) were removed from the 280 DEGs specifically expressed in the anthers, leaving 104 NPGs (Fig. 5). As the four MS lines had tapetums aborted at successive developmental stages, we were able to identify 104 NPGs as anther wall-specific genes, the vast majority of which were considered tapetum-specific genes because their anther walls developed normally with the exception of the distinct abortion of the tapetums (Table 2). We cannot completely rule out that some genes expressed from other tissues are included in the 104 NPGs, although this probability is very low.

Male sterility genes block the developmental pathways of anthers at a certain stage, and lead to abnormal anther development. Because each of the four MS lines showed distinct tapetum abortive phenotypes, and their abnormal characteristics appeared successively during anther development, we could deduce the expression sequence of the NPGs by their expression patterns. The expression sequence of the 55 NPGs could be determined according to the sequential appearance of the tapetum abortive phenotypes (Table 2). First, 28 NPGs that were only down-regulated in the NiCMS line were expressed, followed by seven NPGs down-regulated in both the NiCMS and RGMS lines, then 16 NPGs down-regulated in the NiCMS, RGMS, and OguCMS lines, and finally four NPGs down-regulated in the four MS lines were expressed. It is thought these 55 NPGs constitute the main stream of tapetum development, while the remaining 49 NPGs belonged to bypass ways which also play roles in tapetum development. These results showed that the tapetum development is strongly correlated with gene expression patterns and anther developmental timing. In the eight previously reported tapetumspecific genes, five (ACOS5, A6, LTP12, LAP5, and A9) were detected in our filtered microarray results, although the other three tapetum-specific genes (TSM1, TAP35, and TAP44) were detected in our microarray analysis at variable expression levels in the four MS lines. Because of the strict filter these three tapetum-specific genes were not included in our set of 104 NPGs. There were many noticeable features in the up-regulated genes, with 13 NPGs up-regulated in the OguCMS line, five NPGs up-regulated in both the RGMS and OguCMS lines, and one NPG up-regulated in both the RGMS and DGMS lines (Table 2). This is consistent with the cytological observations of different abnormal tapetum development in the four MS lines.

The tapetum developmental network is regulated by many genetic pathways (Wilson and Zhang 2009). MS mutants occurring at different developmental stages lead to abnormal downstream reactions, including altered tapetum structure and gene expression patterns. These changes are evoked by the presence of MS-associated proteins (Fujii et al. 2010). Only a few previous studies have analyzed gene expression patterns in B. oleracea MS lines (Kang et al. 2008). These studies compared anther gene expression profiles in MS lines with their corresponding fertile lines, allowing for the preferentially expressed anther genes to be identified. Despite their clear contribution to anther developmental pathways, downstream expressed anther wall-specific genes have been overlooked because of the removal of male gametophyte-specific expressed genes.

Function of genes arrested by the four types of B. oleracea MS lines

The distribution of the NPGs was determined in the gene ontology data set (MAS 3.0, http://bioinfo.capitalbio.com/ mas3/) and found to cover virtually all functional categories (Fig. 6). The classification of functional categories revealed that some were enriched in DEGs that had reduced expression levels, including structural molecules, transporters, and physiological processes. These categories are associated with metabolic activities that are dynamic in the tapetum, suggesting a positive role of the tapetum in the regulation of metabolic functions. As we are interested in the genetic mechanism of tapetum abortion in the four MS lines, genes specifically expressed in the tapetum were further analyzed to identify tapetum abortive phenotypes. 
Fig. 6 Gene ontology categorization of non-pollen expressed genes (NPGs) of B. oleracea. The NPGs were placed in 15 functional categories based on the MAS database

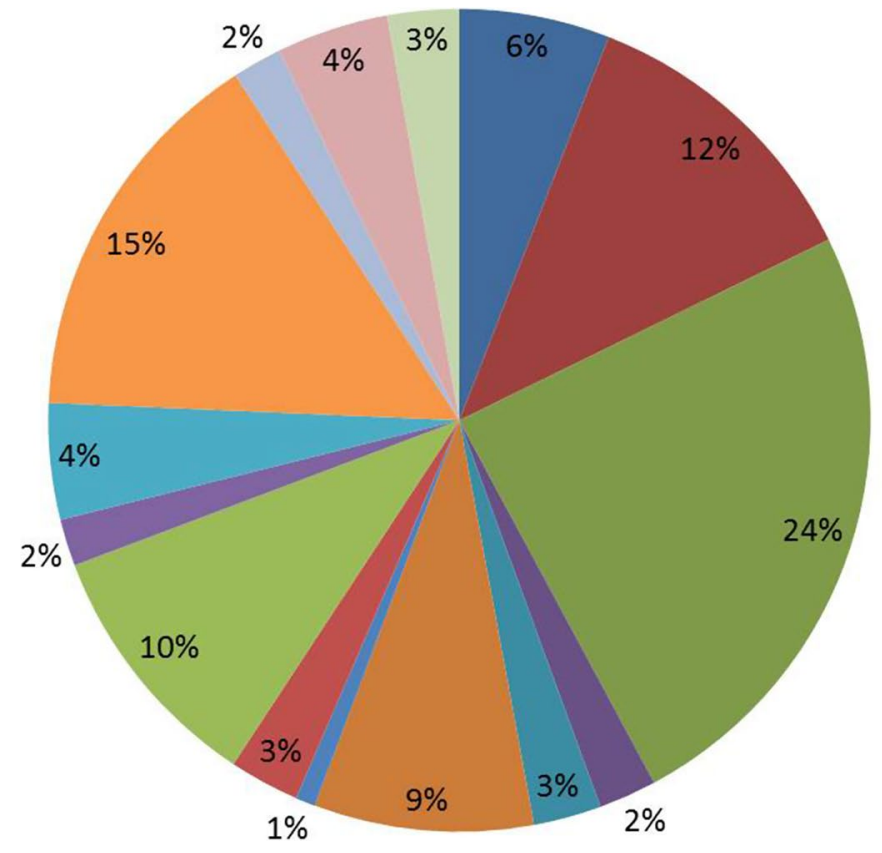

\title{
Sense control probe
}

\author{
Anti-sense probe
}
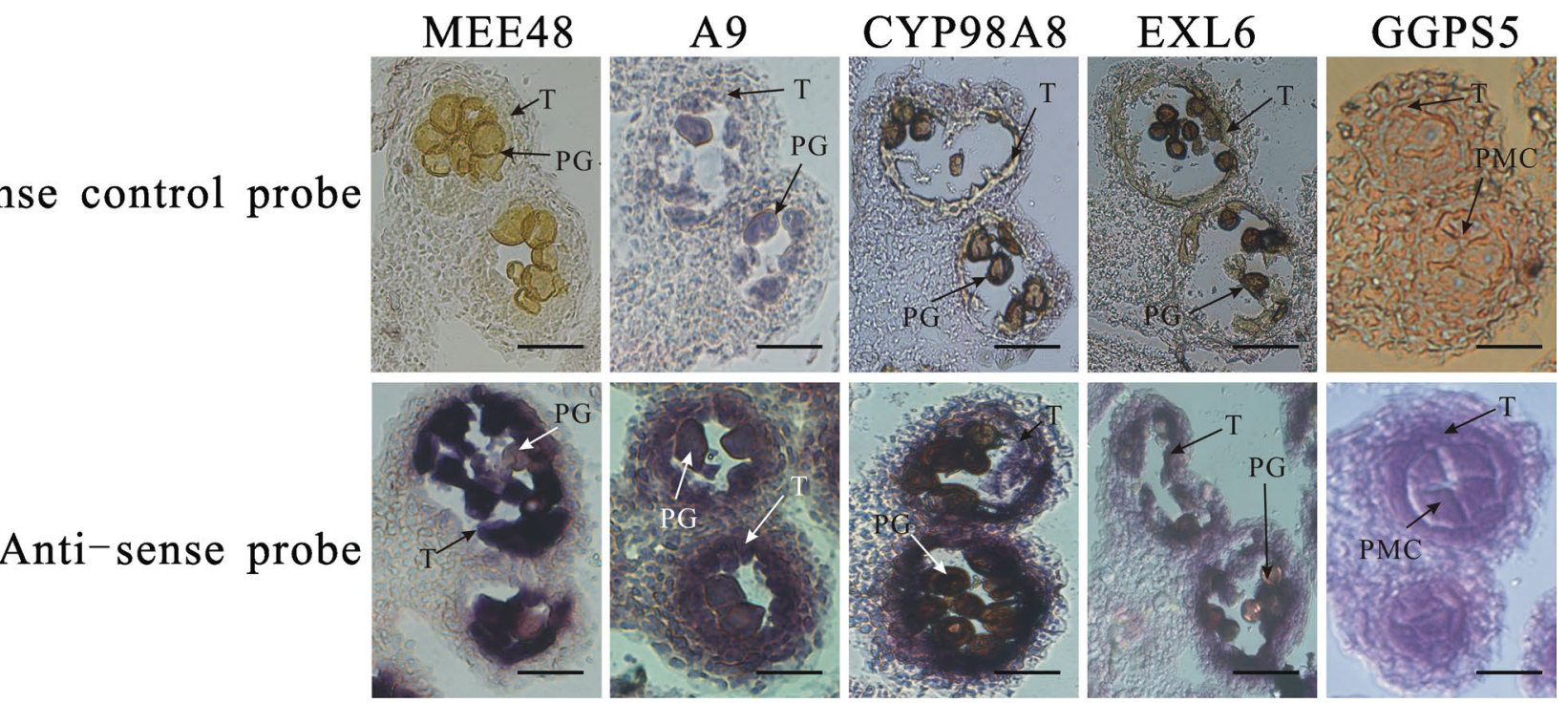

Fig. 7 Five Brassica oleracea NPG mRNAs were localized by in situ hybridization to sections taken from developing anther locules of wild type (Col-0) Arabidopsis flowers. Top line using each of the five non-pollen expressed genes (NPGs) control sense probes. Bottom line using each of the five NPGs anti-sense probe. Dark precipitate indicates hybridization of the probe. $T$ tapetum, $P G$ pollen grain, $P M C$ pollen mother cell. $B a r=70 \mu \mathrm{m}$

identified as NPGs in this study (LTP12, CYP703A2, CYP704B1, LAP5, ACOS5, ABCG26, MYB103, MYB99, WBC27, ATBHLH089, and ATBHLH091) (Table 2). To determine the expression patterns of NPGs, we compared them with other mutant transcriptomes that have been analyzed by bioinformatics filtering. The results showed that $27(26 \%)$ NPGs were also detected in an anther-specific expressed gene set (Xu et al. 2014), 32 (31 \%) NPGs were detected in a stamen-specific expressed gene set that 
excluded pollen-specific expressed genes (Ma et al. 2012). To validate microarray results in anthers, we performed in situ hybridization using five randomly chosen NPG-derived probes and developing wild-type $A$. thaliana flowers (Fig. 7). We used MEE48, A9, CPY98A8, and EXL6 probes that hybridized with anthers when they had developed to the uninucleated microspore stage, respectively. GGPS5 probes were hybridized with anthers when they developed to the pollen mother cell stage. No hybridization signal was observed in locules with microspores and tapetum using any of the NPG sense control probes. However, NPG antisense probes resulted in varying degrees of hybridization to the tapetum. These results showed that our data set, which was generated by bioinformatics filtering, was reliable. Therefore, the NPGs can be seen as potential tapetum-specific expressed genes.

\section{Conclusions}

In this study, four different types of B. oleracea MS lines, covering the whole of anther development, were sampled for microscopy and microarray analysis. A systematic study of the tapetum developmental and molecular phenotypes of the four $B$. oleracea MS lines was performed using the Agilent Arabidopsis 2 Oligo array, which contains 25,000 probes to known or predicted genes. This is the first large-scale trial to explore the spatial and temporal expression patterns of tapetum-specific gene in $B$. oleracea MS lines. The results revealed that most tapetum-specific genes were expressed in a stage-specific manner.

The most significant phenotype of the four $B$. oleracea MS lines is that the anther walls are normally developed, with the exception of the distinct tapetum abortive phenotypes. These abnormal characteristics appeared successively during anther development (Fig. 1). The abortive phenotypes first appears in NiCMS, then in RGMS, followed by OguCMS, and finally in DGMS. A sequential developmental interruption model was proposed to clarify the expression order of the DEGs in plants. MS-associated proteins might directly or indirectly regulate some of the genes involved in tapetum synthesis and degeneration, and then block the expression of a large number of genes involved in normal microspore development. Eliminating sporophytic-and male gametophyte-specific expressed genes identified in the NPGs as anther wall-specific genes, resulted in the majority of remaining genes being tapetum specific. We defined the expression sequence of 55 NPGs based on the sequential developmental interruption model and determined that they are involved in structural molecules, transporters, and physiological processes related to cell wall modification and catalytic activities. The categories suggested the metabolic role of the tapetum in the regulation of anther development. These results outline a methodology to retrieve information on hard to isolate tissues through the comparison of global expression with gene expression in easily obtained mutants. The relationship of anther-expressed genes can be clarified by comparing the sequential cytological appearance of defects in multiple independent MS lines with the same tissues in the wild-type.

Acknowledgments The work was funded by the National High Technology R\&D Program of China (2012AA100101), International Joint Research Grant of Ministry of Science and Technology, P. R. China (2010DFA31730), and National Natural Science Foundation of China (NSFC Grant:30972010). The work was conducted in Key Laboratory of Biology and Genetic Improvement of Horticultural Crops, Ministry of Agriculture, P. R. China and the Sino-Dutch Joint Lab of Horticultural Genomics Technology in Beijing.

Conflict of Interest The authors declare no conflict of interest.

Open Access This article is distributed under the terms of the Creative Commons Attribution License which permits any use, distribution, and reproduction in any medium, provided the original author(s) and the source are credited.

\section{References}

Amagai M, Ariizumi T, Endo M, Hatakeyama K, Kuwata C, Shibata D, Toriyama K, Watanabe M (2003) Identification of anther-specific genes in a cruciferous model plant, Arabidopsis thaliana, by using a combination of Arabidopsis macroarray and mRNA derived from Brassica oleracea. Sex Plant Reprod 15:213-220

Ariizumi T, Amagai M, Shibata D, Hatakeyama K, Watanabe M, Toriyama K (2002) Comparative study of promoter activity of three anther-specific genes encoding lipid transfer protein, xyloglucan endotransglucosylase/hydrolase and polygalacturonase in transgenic Arabidopsis thaliana. Plant Cell Rep 21:90-96

Becker JD, Boavida LC, Carneiro J, Haury M, Feijo JA (2003) Transcriptional profiling of Arabidopsis tissues reveals the unique characteristics of the pollen transcriptome. Plant Physiol 133:713-725

Chang F, Wang Y, Wang S, Ma H (2011) Molecular control of microsporogenesis in Arabidopsis. Curr Opin Plant Biol 14:66-73

de Azevedo Souza C, Kim SS, Koch S, Kienow L, Schneider K, McKim SM, Haughn GW, Kombrink E, Douglas CJ (2009) A novel fatty acyl-CoA synthetase is required for pollen development and sporopollenin biosynthesis in Arabidopsis. Plant Cell 21:507-525

Engelke T, Hülsmann S, Tatlioglu T (2002) A comparative study of microsporogenesis and anther wall development in different types of genic and cytoplasmic male sterilities in chives. Plant Breed 121:254-258

Fang ZY, Sun PT, Liu YM (1984) Brief report: breeding of cytoplasmic male sterile line in cabbage. China Veg 4:42-43

Fang ZY, Sun PT, Liu YM, Yang LM, Hou AF, Wang XW, Bian CS (1995) Preliminary study on the inheritance of male sterility in cabbage line 79-399-438. Acta Hortic (ISHS) 402:414-417

Fang ZY, Sun PT, Liu YM, Yang LM, Wang XW, Zhuang M (2001) Investigation of different types of male sterility and application of dominant male sterility in cabbage [J]. China Veg 1:6-10 
Fellenberg C, Milkowski C, Hause B, Lange P-R, Böttcher C, Schmidt J, Vogt T (2008) Tapetum-specific location of a cationdependent O-methyltransferase in Arabidopsis thaliana. Plant $\mathbf{J}$ 56:132-145

Fujii S, Yamada M, Fujita M, Itabashi E, Hamada K, Yano K, Kurata $\mathrm{N}$, Toriyama K (2010) Cytoplasmic-nuclear genomic barriers in rice pollen development revealed by comparison of global gene expression profiles among five independent cytoplasmic male sterile lines. Plant Cell Physiol 51:610-620

Ge X, Chang F, Ma H (2010) Signaling and transcriptional control of reproductive development in Arabidopsis. Curr Biol 20:R988-R997

Goldberg RB, Beals TP, Sanders PM (1993) Anther development: basic principles and practical applications. Plant Cell 5:1217-1229

Higginson T, Li SF, Parish RW (2003) AtMYB103 regulates tapetum and trichome development in Arabidopsis thaliana. Plant $\mathrm{J}$ 35:177-192

Hird DL, Worrall D, Hodge R, Smartt S, Paul W, Scott R (1993) The anther-specific protein encoded by the Brassica napus and Arabidopsis thaliana A6 gene displays similarity to beta-1,3-glucanases. Plant J 4:1023-1033

Honys D, Twell D (2003) Comparative analysis of the Arabidopsis pollen transcriptome. Plant Physiol 132:640-652

Honys D, Twell D (2004) Transcriptome analysis of haploid male gametophyte development in Arabidopsis. Genome Biol 5:1-13

Hooker TS, Millar AA, Kunst L (2002) Significance of the expression of the CER6 condensing enzyme for cuticular wax production in Arabidopsis. Plant Physiol 129:1568-1580

Kang J, Zhang G, Bonnema G, Fang Z, Wang X (2008) Global analysis of gene expression in flower buds of Ms-cd1 Brassica oleracea conferring male sterility by using an Arabidopsis microarray. Plant Mol Biol 66:177-192

Kao H, Keller W, Gleddie S, Brown G (1992) Synthesis of Brassica oleracea/Brassica napus somatic hybrid plants with novel organeile DNA compositions. Theor Appl Genet 83:313-320

Kim SS, Grienenberger E, Lallemand B, Colpitts CC, Kim SY, CdA Souza, Geoffroy P, Heintz D, Krahn D, Kaiser M, Kombrink E, Heitz T, Suh D-Y, Legrand M, Douglas CJ (2010) LAP6/POLYKETIDE SYNTHASE A and LAP5/POLYKETIDE SYNTHASE B encode hydroxyalkyl $\alpha$-pyrone synthases required for pollen development and sporopollenin biosynthesis in Arabidopsis thaliana. Plant Cell 22:4045-4066

Lou P, Kang J, Zhang G, Bonnema G, Fang Z, Wang X (2007) Transcript profiling of a dominant male sterile mutant $(M s-c d 1)$ in cabbage during flower bud development. Plant Sci 172:111-119

Ma H (2005) Molecular genetic analyses of microsporogenesis and microgametogenesis in flowering plants. Annu Rev Plant Biol 56:393-434

Ma H, Sundaresan V (2010) Chapter thirteen-development of flowering plant gametophytes. In: Marja CPT (ed) Current topics in developmental biology. Academic Press, San Diego

Ma X, Feng B, Ma H (2012) AMS-dependent and independent regulation of anther transcriptome and comparison with those affected by other Arabidopsis anther genes. BMC Plant Biol 12:23

Mariani CDBM, Truettner J, Leemans J, Goldberg RB (1990) Induction of male sterility in plants by a chimeric ribonuclease gene. Nature 347:737-741

McCormick S (1993) Male gametophyte development. Plant Cell 5:1265-1275
Owen H, Makaroff CA (1995) Ultrastructure of microsporogenesis and microgametogenesis in Arabidopsis thaliana (L.) Heynh. ecotype Wassilewskija (Brassicaceae). Protoplasma 185:7-21

Papini A, Mosti S, Brighigna L (1999) Programmed-cell-death events during tapetum development of angiosperms. Protoplasma 207:213-221

Paul W, Hodge R, Smartt S, Draper J, Scott R (1992) The isolation and characterisation of the tapetum-specific Arabidopsis thaliana A9 gene. Plant Mol Biol 19:611-622

Pearson O (1972) Cytoplasmically inherited male sterility characters and flavor components from the species cross Brassica nigra (L) Koch X Brassica oleracea L. Amer Soc Hort Sci J

Piffanelli P, Ross JHE, Murphy DJ (1998) Biogenesis and function of the lipidic structures of pollen grains. Sex Plant Reprod 11:65-80

Pina C, Pinto F, Feijo JA, Becker JD (2005) Gene family analysis of the Arabidopsis pollen transcriptome reveals biological implications for cell growth, division control, and gene expression regulation. Plant Physiol 138:744-756

Sanders PM, Bui AQ, Weterings K, McIntire KN, Hsu YC, Lee PY, Truong MT, Beals TP, Goldberg RB (1999) Anther developmental defects in Arabidopsis thaliana male-sterile mutants. Sex Plant Reprod 11:297-322

Scott R, Hodge R, Paul W, Draper J (1991) The molecular biology of anther differentiation. Plant Sci 80:167-191

Scott RJ, Spielman M, Dickinson HG (2004) Stamen structure and function. Plant Cell 16(Suppl 1):S46-S60

Smyth DR, Bowman JL, Meyerowitz EM (1990) Early flower development in Arabidopsis. Plant Cell 2:755-767

Spurr AR (1969) A low-viscosity epoxy resin embedding medium for electron microscopy. J Ultrastruct Res 26:31-43

Stevens VA, Murray BG (1981) Studies on heteromorphic self-incompatibility systems: the cytochemistry and ultrastructure of the tapetum of Primula obconica. J Cell Sci 50:419-431

Suwabe K, Suzuki G, Takahashi H, Shiono K, Endo M, Yano K, Fujita M, Masuko H, Saito H, Fujioka T, Kaneko F, Kazama T, Mizuta Y, Kawagishi-Kobayashi M, Tsutsumi N, Kurata N, Nakazono M, Watanabe M (2008) Separated transcriptomes of male gametophyte and tapetum in rice: validity of a laser microdissection (LM) microarray. Plant Cell Physiol 49:1407-1416

Varnier A-L, Mazeyrat-Gourbeyre F, Sangwan RS, Clément C (2005) Programmed cell death progressively models the development of anther sporophytic tissues from the tapetum and is triggered in pollen grains during maturation. J Struct Biol 152:118-128

Wellmer F, Riechmann JL, Alves-Ferreira M, Meyerowitz EM (2004) Genome-wide analysis of spatial gene expression in Arabidopsis flowers. Plant Cell 16:1314-1326

Wilson ZA, Zhang DB (2009) From Arabidopsis to rice: pathways in pollen development. J Exp Bot 60:1479-1492

Xu J, Ding Z, Vizcay-Barrena G, Shi J, Liang W, Yuan Z, WerckReichhart D, Schreiber L, Wilson ZA, Zhang D (2014) ABORTED MICROSPORES Acts as a master regulator of pollen wall formation in Arabidopsis. Plant Cell Online 26:1544-1556

Yang YH, Dudoit S, Luu P, Lin DM, Peng V, Ngai J, Speed TP (2002) Normalization for cDNA microarray data: a robust composite method addressing single and multiple slide systematic variation. Nucleic Acids Res 30:e15

Zhang X, Feng B, Zhang Q, Zhang D, Altman N, Ma H (2005) Genome-wide expression profiling and identification of gene activities during early flower development in Arabidopsis. Plant Mol Biol 58:401-419 